\title{
Simulation analysis on policy interaction effects between emission trading and renewable energy subsidy
}

\author{
Jie HUANG (ه), Feng XUE, Xiaofang SONG
}

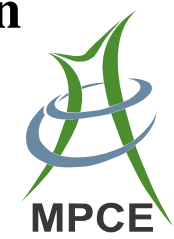

\begin{abstract}
Greenhouse gas emission regulation and renewable energy promotion policies have been implemented in many countries. Yet these two kinds of regulation policies have complex interactions between each other, and can either enhance or reduce the overall emission reduction efficiency. If not well tuned, these regulation policies may deviate from their original intention and lead to unnecessary social cost. Hence, the policy effectiveness, cost effectiveness, and dynamic efficiency of different policy mixtures between emission trading and renewable energy subsidy are studied based on a novel dynamic simulation platform of power economy and power system. Simulation results show that these two kinds of regulation policy can coexist, but a good coordination between the emission trading and the renewable energy subsidy can achieve better emission reduction outcomes.
\end{abstract}

Keywords Dynamic simulation, Energy conservation, Emission reduction, Emission trading, Renewable energy, Policy effectiveness

\section{Introduction}

Recent years, the exhaustion of fossil energy and the environmental concerns of pollutants emission have made the energy conservation and emission reduction necessary.

Received: 26 December 2012/ Accepted: 20 May 2013/Published Online: 9 August 2013

(C) The Author(s) 2013. This article is published with open access at Springerlink.com

J. HUANG, F. XUE, X. SONG, NARI Group Corporation (State Grid Electric Power Research Institute), Nanjing 210003, China

$(\bowtie)$ e-mail: huangjie1@ @gepri.sgcc.com.cn

F. XUE

e-mail: xuefeng2@sgepri.sgcc.com.cn

X. SONG

e-mail: songxiaofang@sgepri.sgcc.com.cn
The power industry, which has been relying on fossil fuel as main primary energy for a long time, is emission intensive. In order to reduce the dependence on fuel energy and greenhouse gas emission, various regulation measures have been proposed and implemented, which can be roughly categorized into two kinds of greenhouse gas emission regulation and renewable energy promotion. Emission regulation and renewable energy promotion are regulation measures in two aspects, yet aiming at the same goal of achieving energy conservation and emission reduction targets. Therefore, in addition to the physical restrictions intrinsic to itself, power systems are nowadays facing more constraints from external domains, such as primary energy and emissions.

In [1], a novel concept, called the "generalized congestions" was proposed to describe those factors affecting both the competition level and the efficiency of power markets. Market power is defined as the market participant's capability to influence the market efficiency with the aid of generalized congestions, and generalized market power reflects its capability to influence the social welfare. Regulation measures, like other generalized congestions, could influence the energy and capital flows in power systems. Thus, the regulation power is a special market power, which can also reduce market efficiency if it is not well designed.

In most countries, emission regulation and renewable energy promotion coexist, in which complex interactions are likely to happen. In [2], interactions between emission regulation and renewable energy (RES) promotion were categorized into direct interaction, indirect interaction, and trading interaction. The detailed interaction model is elaborated in this paper (shown in Fig. 1). If the interactive modes or key parameters of these regulation measures are adopted by ex-ante simulation evaluation, the unnecessary policy risk and social cost losses may be avoided. 


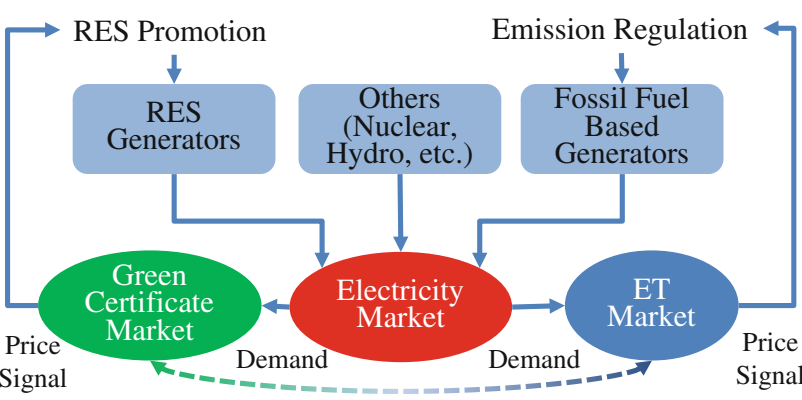

Fig. 1 Interactions between renewable energy promotion and emission regulation

\section{Existing regulation policies for greenhouse gas emission and renewable energy promotion}

\subsection{Regulation of greenhouse gas emission}

Typical regulation methods are carbon tax and emission trading (ET). Carbon tax is a Pigovian tax levied on the carbon content of fuels [3]. The Australia government introduced the carbon tax law in December 2011, which forced about 300 of the worst-polluting firms to pay an AUD $\$ 23$ levy for every ton of greenhouse gases they produced. The problem with carbon tax is to determine a proper tax rate. The target of carbon tax is to internalize the externality of emission, however the marginal externality cost is difficult to be discovered. Emission trading is a market-based approach to control the pollution by providing economic incentives for achieving pollutant emission reductions. The basic methodology of emission trading is Coase theorem, which solves the externality problem by defining property rights and market-based mechanisms. The emission trading is a discovering process for marginal external cost. Theoretically, it could achieve the emission reduction target in the most efficient way when the transaction cost is near zero. Emission Trading Scheme (ETS) has already been implemented in many countries and districts, such as the Danish $\mathrm{CO}_{2}$ trading program (from 2001 to 2003), UK ETS (from 2002 to 2006), and EU ETS (2005). In [4], a detailed survey of EU ETS is given, including the origins and history, the allocation of allowances, the implications of competitiveness and the distribution of costs and benefits, etc.

\subsection{Renewable energy promotion}

Regulation of greenhouse gas emissions will introduce extra emission cost to fuel-based generation, which, to some extent, will make renewable energy generation relatively more competitive. However, researches show that only if the carbon tax or the emission price is much higher than the present value, can the renewable energy be truly competitive. So, in many countries, various policies for
Table 1 Different mechanisms for renewable energy promotion

\begin{tabular}{llc}
\hline $\begin{array}{l}\text { Incentive } \\
\text { mode }\end{array}$ & Price driven & Quantity driven \\
\hline $\begin{array}{r}\text { Investment } \\
\text { incentive }\end{array}$ & $\begin{array}{c}\text { Investment subsidy; low } \\
\text { interest loan }\end{array}$ & $\begin{array}{c}\text { Investment bidding } \\
\text { system }\end{array}$ \\
$\begin{array}{r}\text { Generation } \\
\text { incentive }\end{array}$ & $\begin{array}{c}\text { Feed-in-tariff subsidy; } \\
\text { price premium }\end{array}$ & $\begin{array}{c}\text { Renewable portfolio } \\
\text { standard }\end{array}$ \\
\hline
\end{tabular}

renewable energy promotion are applied to increase the competitiveness of renewable energy directly. The existing policies for renewable energy promotion can be categorized into two kinds of "price driven" and "quantity driven" based on their different regulation targets, and "investment incentive" and "generation incentive" based on their different incentive targets (shown in Table 1).

\subsection{Existing research methods}

In electricity market research, the major modelling methods include optimization model based, game equilibrium model based and simulation model based. In [5], a stateof-the-art review on modeling methods for decision making optimization in the electricity spot market was given. When studying the emission reduction related decision making problems, similar modelling methods are adopted. In [6], optimization model was used to investigate the effects of emission constraints and emission trading scheme on the generation scheduling outcome. In [7], Cournot equilibrium model was used to analyze the potential profit impacts and possible compensation of potential emission trading scheme on generation companies. As for power system energy policy studies, optimization and game equilibrium models are not applicable since the target problem is too complicated and comprises different market participants. Popular modelling methods of the power system energy policies include the computable general equilibrium (CGE) model and agentbased computational economics (ACE) model. CGE models are popular for policy analysis, which compromise of economic models using actual economic data to estimate how an economy might react to changes of policy, technology or other external factors. CGE models have been widely used in environmental policy researches to analyze the impact of different emission allowance allocation methods on emission reduction effects [8] and the impact of EU-wide emission trading on the reduction cost [9]. The ACE model-based method is to study the economics and emissions by evolving systems of autonomous interacting agents [10]. ACE models have been adopted to study the long-term impact of emission trading on generation emissions [11,12] and the design of emission trading scheme [13], and the impact of the policies of renewable energy promotion on renewable energy investment [14]. 


\section{Simulation tool and models}

The dynamic simulation platform for power economy and power system (DSPES) was first proposed in [15], which is a novel simulation platform supporting multicriteria, multi-participant dynamic simulation. Based on the dynamic model of power systems and power economy, DSPES supports the experimental study of power industry, providing quantitative risk analysis function and decision support for different participants. In this paper, DSPES is used for case studies. Mid-term simulation will be run to obtain the simulation results in 1 year.

\subsection{Generation model}

1) Marginal cost of fossil fuel-based generator. The marginal cost $c_{\mathrm{f}}(€ / \mathrm{MWh})$ for fossil fuel-based generator consists of marginal generation cost $c_{\mathrm{fg}}$ and marginal emission cost $c_{\mathrm{fe}}(€ / \mathrm{MWh})$

$c_{\mathrm{f}}=c_{\mathrm{fg}}+c_{\mathrm{fe}}=p_{\mathrm{f}} / e+p_{\mathrm{e}} \times r_{\mathrm{fe}}$,

where $c_{\mathrm{fg}}=p_{\mathrm{f}} / \mathrm{e}, p_{\mathrm{f}}(€ /$ ton $)$ is the fuel price and $e$ $(\mathrm{MWh} /$ ton$)$ is the efficiency; $c_{\mathrm{fe}}=p_{\mathrm{e}} \times r_{\mathrm{e}}, p_{\mathrm{e}}(€ /$ ton $)$ is the emission price and $r_{\mathrm{fe}}(\mathrm{ton} / \mathrm{MWh})$ is the emission rate.

2) Emission trading strategy. The emission trading quantity $q_{\mathrm{f}, i, t}^{\mathrm{e}}$ of fossil fuel-based generator $i$ at day $t$ is

$q_{\mathrm{f}, i, t}^{\mathrm{e}}=e_{i, t}-b_{i}^{\mathrm{e}} \times r_{t}^{1}$,

where $e_{i, t}$ is the emission quantity of generator $i$ at day $t, b_{i}^{\mathrm{e}}$ is the emission allowance budget of generator $i$ at day $t$, and $r_{t}^{1}$ is ratio of load level at day $t$ with respect to annual total load.

3) Marginal cost of renewable energy. The marginal cost $c_{\mathrm{r}}(€ / \mathrm{MWh})$ for renewable energy is the marginal generation cost $c_{\mathrm{rg}}(€ / \mathrm{MWh})$ minus feed-in-tariff subsidy $p_{\mathrm{r}}(€ / \mathrm{MWh})$ as follows

$c_{\mathrm{r}}=c_{\mathrm{rg}}-p_{\mathrm{r}}$.

\subsection{Electricity market model}

Generation Companies (GENCOs) will trade in the spot electricity market on daily basis. Suppose that the demand is inelastic and every unit reports their marginal cost. Uniform clearing pricing method is adopted to clear the market.

\subsection{Emission market model}

In this model, emission trading is carried out on daily basis, and GENCOs are considered as price takers, who report their everyday emission allowance demand to the

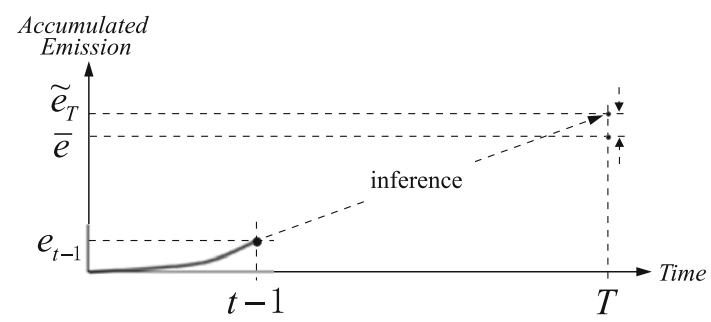

Fig. 2 Basic principle of the "demand-price" model

emission market. Daily emission price $p_{\mathrm{e}}$ will then be generated based on a "demand-price" model.

In this "demand-price" model, $p_{\mathrm{e} t}$ (emission price at day $t$ ) is calculated based on an inference from the accumulated emission allowance demand before day $t$ to the annual overall emission demand. Its basic principle is illustrated in Fig. 2.

$p_{\mathrm{e} t}=\bar{p}_{\mathrm{e}}+\lambda \frac{\left(\tilde{e}_{\mathrm{T}}-e_{t-1}\right)-\left(\bar{e}-e_{t-1}\right)}{\bar{e}-e_{t-1}}$,

$e_{t-1}=\sum_{k=1}^{t-1} \sum_{n=1}^{N} q_{\mathrm{f}, n, k}^{\mathrm{e}}$,

$\tilde{e}_{\mathrm{T}}=\sum_{k=1}^{t-1} \sum_{n=1}^{N} q_{\mathrm{f}, n, k}^{\mathrm{e}} / \sum_{k=1}^{t-1} r_{k}^{1}$,

where $\bar{p}_{\mathrm{e}}$ is the average price in emission market, $\lambda$ is the emission price factor, $e_{t-1}$ is the accumulated emission allowance demand before day $t ; \tilde{e}_{\mathrm{T}}$ is the inference value of annual overall emission allowance demand based on $e_{t-1}, \bar{e}$ is the preset annual overall emission cap and $r_{k}^{1}$ is the daily load proportion (in day $k$ ) with respect to annual overall load.

This emission market "demand-price" model tries to simulate the annual emission price dynamics. Parameters in this model has been tuned based on actual EU ETS emission market price statistics, $\bar{p}_{\mathrm{e}}$ is set to $20 € /$ ton, $\lambda$ is set to 1,000 , and price cap and floor are set to 40 and $0 € /$ ton, respectively.

The following case studies show that the model can reasonably reflect the emission price dynamics.

\subsection{Evaluation index}

1) Social cost (SC). The social cost must be comprehensively evaluated, covering each kind of cost incurred and possible social benefits. In this sense, at least electricity purchasing cost (PC), subsidy (S), and social benefits (B) should be considered. In this paper: $\mathrm{SC}=\mathrm{PC}+\mathrm{S}-\mathrm{B}$. It should be mentioned that, usually the fiscal revenue of selling emission allowance or the carbon tax will be used to encourage clean energy development, which is the social benefits in this paper. 
2) Overall emission $(O E)$. The overall emission of the whole system is used to evaluate the effectiveness of policies, rather than the emission per MWh or per GDP.

3) Cost efficiency (CE). Cost efficiency is needed to compare the efficiency of one policy with another one. $\mathrm{CE}=\Delta \mathrm{OE} / \Delta \mathrm{SC}$, where $\Delta \mathrm{OE}$ and $\Delta \mathrm{SC}$ are the increments of $\mathrm{OE}$ and $\mathrm{SC}$, respectively.

Dynamic efficiency can be evaluated by the profit accumulation of each kind of GENCO.

\section{Case studies}

IEEE 39-bus system is chosen for case studies, Fig. 3 shows the annual load curve, and three kinds of GENCO are set in the system: high emission GENCO (HIGH) which owns fossil fuel-based generators (mainly coal-based) with high emission rate, low emission GENCO (LOW) which owns fossil fuel-based generators (mainly gas-based) with low emission rate, and renewable GENCO (RENEWABLE) which owns renewable energy generators.

And in this paper, feed-in-tariff subsidy and emission trading are selected as the typical renewable energy promotion and emission regulation measures, respectively, as shown in Fig. 4.

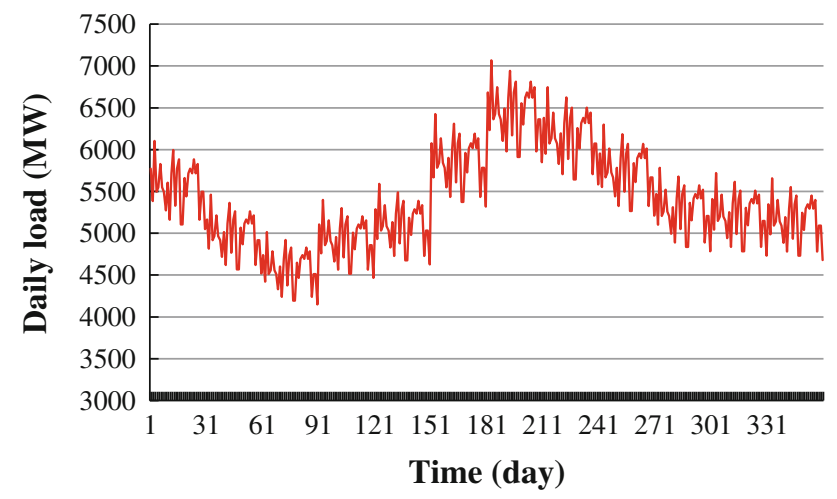

Fig. 3 Annual load curve

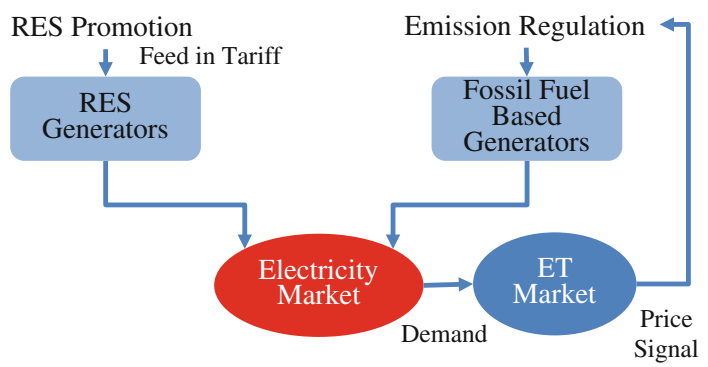

Fig. 4 Interaction model
Table 2 Unit parameters

\begin{tabular}{lcll}
\hline Unit type & $\begin{array}{l}\text { Installed } \\
\text { capacity }(\mathrm{MW})\end{array}$ & $\begin{array}{l}\text { Generation marginal } \\
\text { cost }(€ / \mathrm{MWh})\end{array}$ & $\begin{array}{l}\text { Emission rate } \\
(\mathrm{t} / \mathrm{MWh})\end{array}$ \\
\hline COAL_A & 360 & 20.0 & 0.85 \\
COAL_B & 200 & 25.0 & 1.00 \\
COAL_C & 80 & 30.3 & 1.20 \\
GAS_A & 240 & 32.0 & 0.35 \\
GAS_B & 50 & 50.0 & 0.70 \\
BIO & 80 & 60.0 & 0.00 \\
WIND & 1,500 & 70.0 & 0.00 \\
\hline
\end{tabular}

Table 3 Unit distribution

\begin{tabular}{lll}
\hline $\begin{array}{l}\text { Bus } \\
\text { number }\end{array}$ & Unit & GENCO type \\
\hline 30 & COAL_B $\times 1$, COAL_C $\times 1$, & HIGH \\
& GAS_A $\times 1$, GAS_B $\times 3$ \\
32 & COAL_B $\times 2$, GAS_A $\times 3$ & \\
33 & GAS_A $\times 2$, GAS_B $\times 2$ & LOW \\
34 & COAL_C $\times 4$ & LOW \\
35 & COAL_B $\times 1$, GAS_A $\times 2$, & HIGH \\
& GAS_B $\times 1$ & LOW \\
36 & COAL_B $\times 4$ & \\
37 & COAL_C $\times 4$ & LOW \\
38 & COAL_B $\times 3$, COAL_C $\times 2$ & HIGH \\
39 & COAL_A $\times 2$ & LOW \\
39 & BIO $\times 6,6 I N D \times 1$ & HIGH \\
\hline
\end{tabular}

Six types of generator are considered in the case study (shown in Table 2), among them there are three types of coal-based generator, two types of gas-based generator, one type of bio power plant, and one type of wind turbine. And their distributions in a power system are shown in Table 3.

\subsection{First case study: influences of emission regulation strength}

In the first case study, the policy of renewable energy promotion is fixed, and the impact of different emission regulation strengths will be evaluated by scenario simulations.

In all scenarios, feed-in-tariff subsidy is set for renewable energy generators. Here, $50 \%$ means that the subsidy will cover $50 \%$ of the renewable energy generator cost (shown in Table 4).

Scenario 1 is set as the Business as Usual scenario. In Scenarios 2-4, emission trading is implemented and the percentage in Table 4 implicates its target of emission reduction percentage compared with the emission level in Scenario 1. 
Table 4 Simulation scenarios (first case study)

\begin{tabular}{lllll}
\hline Scenario & 1 & 2 & 3 & 4 \\
\hline $\begin{array}{l}\text { Target of emission reduction percentage (emission } \\
\text { trading) }(\%)\end{array}$ & 5 & 10 & 15 \\
$\begin{array}{l}\text { Percentage of feed-in-tariff subsidy referred to } \\
\text { renewable energy generator cost (renewable } \\
\text { energy promotion) }(\%)\end{array}$ & \multicolumn{2}{c}{50} \\
\hline
\end{tabular}

Table 5 Simulation results (first case study)

\begin{tabular}{lllll}
\hline Scenario & 1 & 2 & 3 & 4 \\
\hline Total emissions $\left(\right.$ ton $\left.\times 10^{6}\right)$ & 1.4995 & 1.4245 & 1.3491 & 1.2656 \\
Social cost $\left(€ \times 10^{6}\right)$ & 70.6 & 69.9 & 70.2 & 76.6 \\
Emission reduction $(\%)$ & $\times$ & 5.0 & 10.0 & 15.6 \\
Cost efficiency (ton/€) & $\times$ & $\times$ & 0.2513 & 0.0237 \\
\hline
\end{tabular}

Then simulations are conducted on the simulation platform DSPES, simulation results are shown in Table 5. It can be found in Table 5 that in the aspect of all emissions social cost, the simulation results of Scenario 1 are inferior to that of Scenario 2, which is due to the absence of emission regulation.

In Scenarios 2-4, as the regulation strength increases, the total emissions decrease, while the social cost increases. Among them, Scenario 2 achieves the lowest social cost, and the cost efficiency of Scenarios 3-4 is calculated compared with Scenario 2. Scenario 3 obtains the best cost efficiency $(0.2513$ ton/€), which means the reduction of one more ton emission cost only $€ 3.98$.

So in this case study, considering the total emission reduction and cost efficiency, Scenarios 2 and 3 are better choices.

Figure 5 shows the profit accumulation for different kinds of GENCO under each scenario.

As the emission regulation strengthens from Scenarios $1-4$, more and more profit can be obtained for "RENEWABLE" due to its relatively increased competitiveness, which will stimulate more and more renewable generation investments in the long run; profit accumulation for

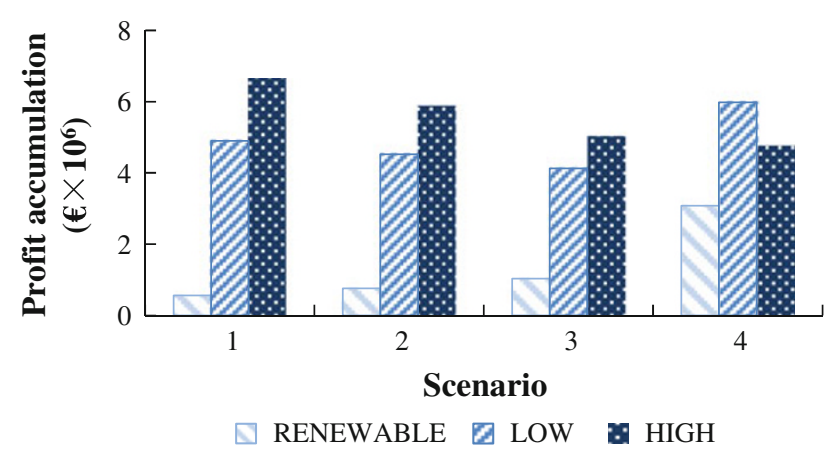

Fig. 5 Profit accumulation of different GENCOs under different scenarios
"HIGH" decreases due to the increase of extra emission cost, its generators will at last act as the peak load units.

Profit accumulation for "LOW" will decrease at the beginning (Scenarios 1-3), because the emission cost is not high enough to compete with "HIGH", while the "RENEWABLE" get more market share. Then, the profit accumulation increases from Scenarios 3-4, because now the emission cost is high enough to compete with "HIGH".

Figures 6, 7, and 8 show the emission price dynamics (in 1 year) at different levels of emission regulation strength. The tougher the regulation, the higher the average emission price is.

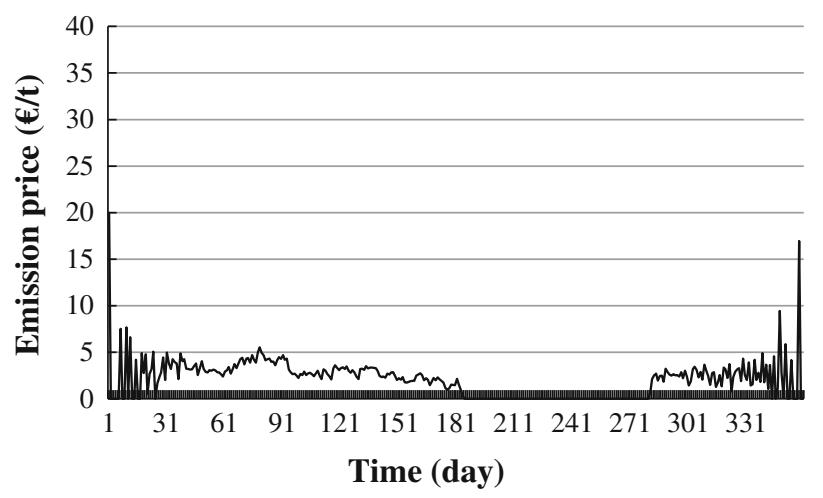

Fig. 6 Emission price dynamics (Scenario 2)

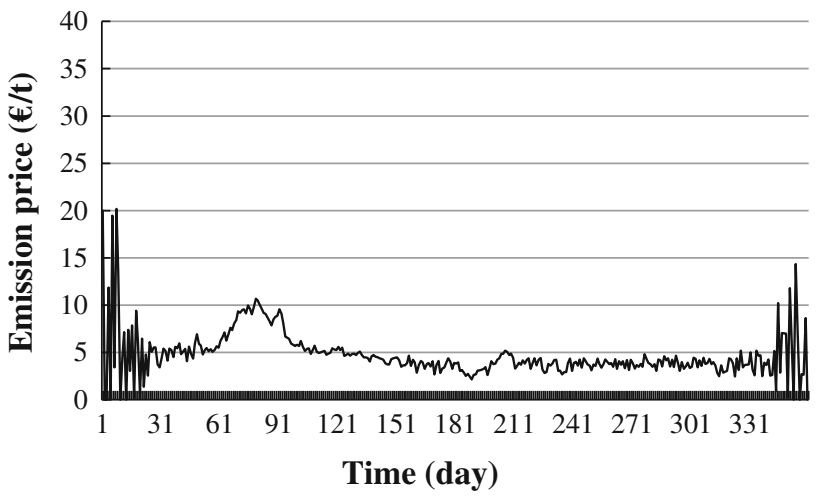

Fig. 7 Emission price dynamics (Scenario 3)

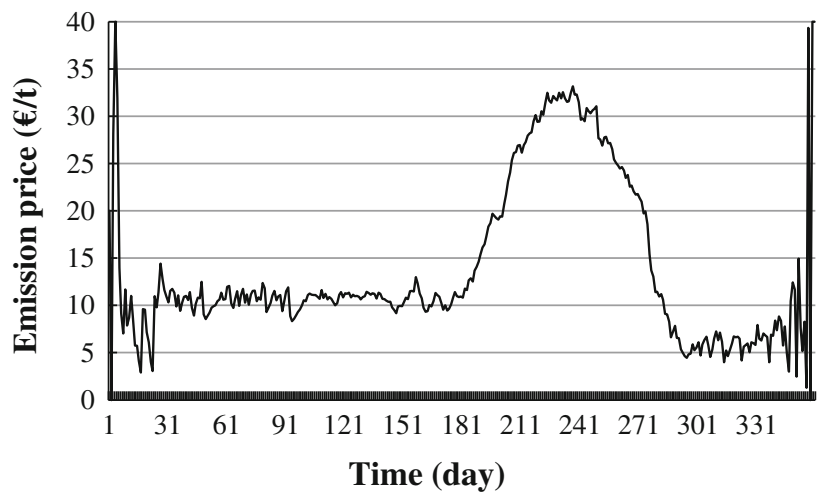

Fig. 8 Emission price dynamics (Scenario 4) 
4.2 Second case study: influences of renewable energy promotion strength

In the second case study, emission regulation policy is fixed, and the impact of different renewable energy promotion strengths is evaluated by simulation scenarios.

Scenario 2 in the first case study is chosen as a benchmark scenario in this case study. The change of renewable energy promotion strength is reflected by different subsidy percentages (shown in Table 6).

Compared with that of Scenario 2, the social cost increases with the growth of subsidy percentage, but the quantity of emission reduction is negligible (shown in Table 7). Considering the cost efficiency, Scenarios 5-7 are inefficient.

In Scenario 5, due to insufficient renewable energy promotion, renewable energy generators cannot compete with fossil fuel-based generators. The latter will account for large market share, and the demand for emission allowance rises, leading to relatively high emission price (shown in Fig. 9).

As the efforts to promote renewable energy generation are enhanced in Scenarios 6 and 7, the excessive feed-intariff will greatly enhance the competitiveness of renewable energy generators, which will cut the market share of fossil fuel-based generators. Therefore, the demand for emission allowance is lowered, and the emission price goes down, which is zero during the majority time (Figs. 10, 11).

In this case study, the excessive renewable energy promotion will twist the emission price signal, which leads to the ineffectiveness of the emission regulation. This is the negative effect of the interaction between renewable energy promotion and emission regulation.

Table 6 Simulation scenarios (second case study)

\begin{tabular}{lllll}
\hline Scenario & 5 & 2 & 6 & 7 \\
\hline $\begin{array}{l}\text { Target of emission reduction percentage } \\
\text { (emission trading) (\%) }\end{array}$ & & 5 & & \\
$\begin{array}{l}\text { Percentage of feed-in-tariff subsidy referred to } \\
\text { renewable energy generator cost (renewable } \\
\text { energy promotion) }(\%)\end{array}$ & 25 & 50 & 75 & 100 \\
\end{tabular}

Table 7 Simulation results (second case study)

\begin{tabular}{lllll}
\hline Scenario & 5 & 2 & 6 & 7 \\
\hline Total emissions $\left(\right.$ ton $\left.\times 10^{6}\right)$ & 1.4233 & 1.4245 & 1.4195 & 1.4195 \\
Social cost $\left(€ \times 10^{6}\right)$ & 71.2 & 69.9 & 77.8 & 82.5 \\
Cost efficiency (ton/€) & 0.0009 & $\times$ & 0.0006 & 0.0004 \\
\hline
\end{tabular}

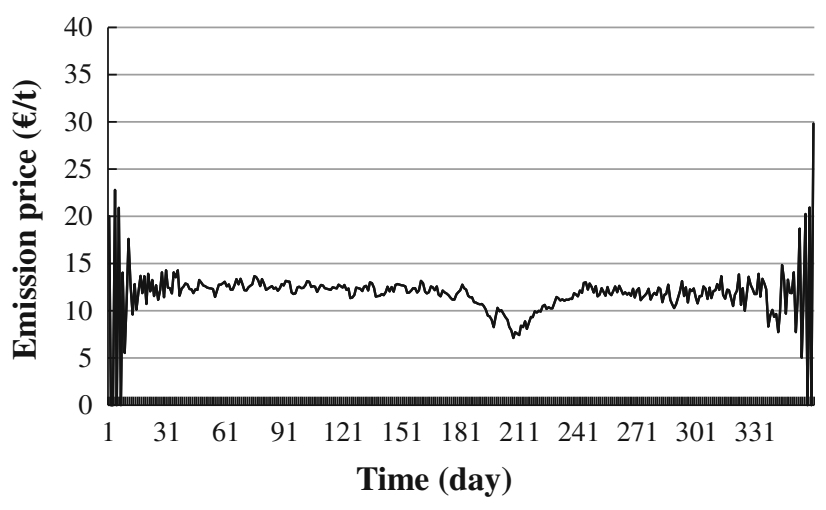

Fig. 9 Emission price dynamics (Scenario 5)

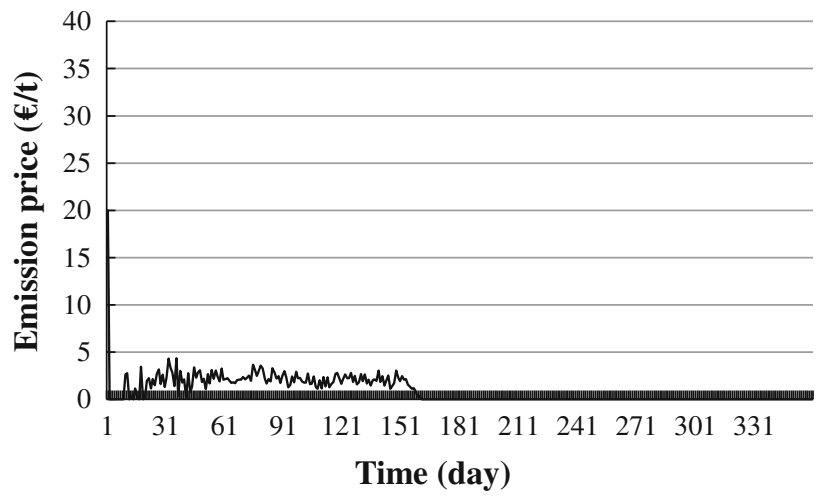

Fig. 10 Emission price dynamics (Scenario 6)

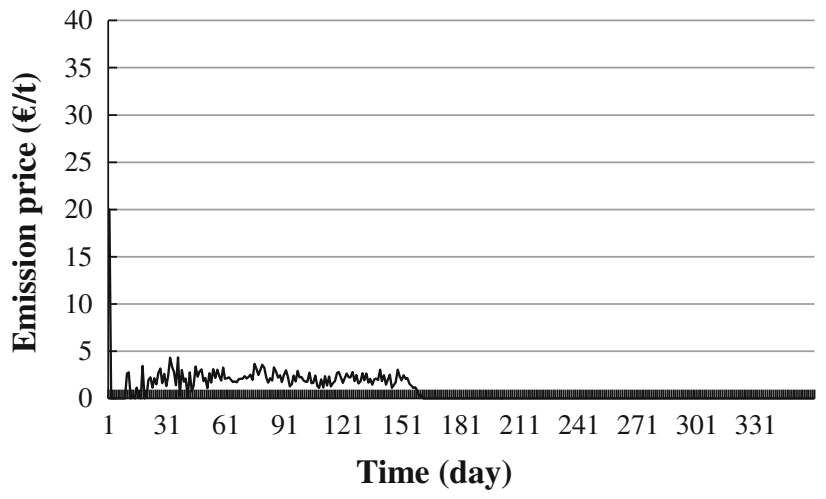

Fig. 11 Emission price dynamics (Scenario 7)

\section{Conclusion}

In this paper, based on the simulation platform DSPES, interactions between greenhouse gas emission regulation and renewable energy promotion in electric power industry are studied. The policy effect is evaluated by the social cost, overall emission, cost efficiency, and the economic incentive to different GENCOs. Case studies show that neither emission regulation nor renewable energy promotion can achieve the most efficient emission reduction 
outcome alone. The two measures will coexist for a long period of time. If not well designed, they will impose negative effects on each other. In the case study, excessive renewable energy promotion may twist the emission price, thus leading to inefficient emission reduction. The DSPES turns out to be a very useful tool for policy analysis, which can be used as a "wind tunnel" before the implementation of energy policies.

Acknowledgments This work was jointly supported by the Major Projects on Planning and Operation Control of Large Scale Grid, State Grid Corporation of China (SGCC-MPLG001-2012), State Grid EPRI Project (YS11002), and the National Natural Science Foundation of China (91024028).

Open Access This article is distributed under the terms of the Creative Commons Attribution License which permits any use, distribution, and reproduction in any medium, provided the original author(s) and the source are credited.

\section{References}

[1] Xue Y, Li T, Yin X et al (2010) A research framework for generalized congestions and market power. Autom Electric Power Syst 34(21):1-10 (in Chinese)

[2] Sorrel S, Sijm J (2005) Carbon trading in the policy mix. Oxf Rev Econ Policy 19(3):420-437

[3] Hoeller P, Wallin M (2010) Energy prices, taxes and carbon dioxide emissions. OECD Econ Stud 17:91-105

[4] Convery FJ (2009) Reflections-the emerging literature on emissions trading in Europe. Rev Environ Econ Policy 3(1): $121-137$

[5] Li G, Shi J, Qu XL (2010) Modeling methods for GenCo bidding strategy optimization in the liberalized electricity spot marketa state-of-the-art review. Energy 36(8):4686-4700

[6] Kockar I, Conejo AJ, McDonald JR (2009) Influence of the emissions trading scheme on generation scheduling. Int J Electr Power Energy Syst 31(9):465-473

[7] Zhou X, James G, Liebman A et al (2010) Partial carbon permits allocation of potential emission trading scheme in Australian electricity market. IEEE Trans Power Syst 25(1):543-553
[8] Edwards TH, Hutton JP (2001) Allocation of carbon permits within a country: a general equilibrium analysis of the United Kingdom. Energy Econ 23(4):371-386

[9] Böhringer C (2002) Industry-level emission trading between power producers in the EU. Appl Econ 34(4):523-533

[10] Tesfatsion L (2003) Agent-based computational economics. ISU economics working paper No. 1. Iowa State University, Ames, IA, USA

[11] Chappin EJL, Dijkema GPJ (2009) On the impact of $\mathrm{CO}_{2}$ emission-trading on power generation emissions. Technol Forecast Soc Change 76(3):358-370

[12] Weidlich A, Sensfuß F, Genoese M et al (2008) Studying the effects of $\mathrm{CO}_{2}$ emissions trading on the electricity market: a multi-agent-based approach. In: Antes R, Hansjurgens B, Letmathe $\mathrm{P}$ (eds) Emissions trading. Springer, New York

[13] Wang J, Koritarov V, Kim JH (2009) An agent-based approach to modeling interactions between emission market and electricity market. In: 2009 IEEE Power \& Energy Society General Meeting, Calgary, AB, Canada, 26-30 July 2009, pp 1-8

[14] Sensfuss F, Ragwitz M, Genoese M (2006) Simulating the expansion of renewable electricity generation in Germany-an agent-based approach. In: Proceedings of the 29th IAEE International Conference, Potsdam, Germany, 7-10 Jun 2006, pp 75-76

[15] Huang J, Xue Y, Xu J et al (2011) Dynamic simulation platform for power market and power system, part I: function design. Autom Electric Power Syst 35(10):16-22 (in Chinese)

\section{Author Biographies}

Jie HUANG obtained his Ph.D. degree from Nanjing University of Science and Technology in 2011. His research interests include electricity market modeling and simulation, risk management, and policy issues related with emission trading.

Feng XUE obtained his Ph.D. degree from the University of Bath, UK in 2008. His main research field is power system analysis and control.

Xiaofang SONG was born in Hebei in China, on September 23, 1980. She obtained her B.Sc. and M.Sc. degrees from Nanjing University of Science and Technology in 2003 and 2005 respectively, all in Electrical Engineering. Her main research field is power system stability analysis and control. 